\title{
LUT
}

Lappeenranta

University of Technology

\section{Use of filter aids to improve the filterability of enzymatically hydrolyzed} biomass suspensions

\author{
Kinnarinen Teemu, Golmaei Mohammad, Häkkinen Antti
}

This is a Final draft version of a publication

published by American Chemical Society

in Industrial \& Engineering Chemistry Research

DOI: $10.1021 / \mathrm{ie} 4021057$

Copyright of the original publication: (@) 2013 American Chemical Society

Please cite the publication as follows:

Kinnarinen, T., Golmaei, M., Häkkinen, A. Use of filter aids to improve the filterability of enzymatically hydrolyzed biomass suspensions, Industrial \& Engineering Chemistry Research, 2013, 52:14955 - 14964. DOI: 10.1021/ie4021057

This is a parallel published version of an original publication. This version can differ from the original published article. 


\title{
Use of Filter Aids to Improve the Filterability of Enzymatically Hydrolyzed Biomass Suspensions
}

\author{
Teemu Kinnarinen*, Mohammad Golmaei, Antti Häkkinen \\ Laboratory of Separation Technology, LUT Chemistry, Lappeenranta University of \\ Technology, P.O. Box 20, FIN-53851 Lappeenranta, Finland \\ ${ }^{*}$ Corresponding author: E-mail: teemu.kinnarinen@,lut.fi; Tel.: +358 405621398
}

Keywords: Cardboard waste, Filtration, Enzymatic hydrolysis, Bioethanol, Filter aids

\begin{abstract}
Filter aids are used in challenging filtration applications, such as the deliquoring of biomass suspensions and separation of fine particles from liquids. Organic filter aids, typically composed of cellulose, may be the preferred option in the case of bioprocesses, because their energy content can be recovered together with the primary filter cake. In this study, a laboratory scale pressure filter was used in order to investigate the effect of various filter aids on the filtration of an enzymatically hydrolyzed biomass suspension. Various organic and inorganic filter aids were used in two modes: as a body feed and as a precoat. According to the results, the average specific resistance of the cakes could be best reduced using the body feed mode. Filter aids also helped to reduce the moisture content of the cakes and to increase the corresponding filtration capacities. Additionally, a process scheme enabling utilization of the solids was proposed.
\end{abstract}

\section{INTRODUCTION}

Efficient separation operations are one of the prerequisites for the industrial production of liquid biofuels. Separations are typically necessary at several process steps and they are a major contributor to the capital and operating cost, as well as the environmental impact. In the case of bioethanol production, enzymatic hydrolysis of lignocellulosic materials to fermentable sugars is regarded as a potential technology for utilizing the energy content of plant biomass. ${ }^{1}$ Industrial production of lignocellulosic bioethanol is close to successful implementation ${ }^{2}$, although a number of limitations ${ }^{3}$ still remain. Depending upon the selected process layout, the number and type of physical separation stages may vary. Forms of separation include screening, filtration, centrifugation, and membrane separation. Different processing alternatives have been introduced and studied by, among others, Balat ${ }^{4}$, Cardona and Sanchez ${ }^{5}$, Hamelinck et al. ${ }^{6}$, Huang ${ }^{7}$, and Kochergin and Miller ${ }^{8}$. The nature of the biomass suspension, either after hydrolysis, fermentation, or a combination, makes efficient separation difficult. Solid-liquid separation, and filtration in particular, has been observed to be challenging. This is usually caused by fine particles, lignin and partially hydrolyzed, but highly compactible, cellulose that do not settle easily in centrifuges but also 
form a relatively impermeable cake in a filter. In cake filtration, the average specific resistance of a filter cake is influenced by several factors, including the particle size and shape, porosity, tortuosity of the flow channels, and chemical phenomena taking place between the phases. ${ }^{9}$ In the present study, the solid content of the biomass suspension is high enough to rapidly form a filter cake on a filter cloth in a pressure filter. It is, therefore, important to distinguish between depth filtration, which is typically used for adsorptive removal of trace amounts of solids, and cake filtration which is investigated in this paper.

Filter aids can be used to improve the performance of challenging cake filtration operations if other techniques, such as the proper selection of a filter cloth, an increased driving force, pretreatments and pre-classifications, are not enough to provide a sufficient filtration rate. In some cases, polymeric flocculants may also facilitate the separation. ${ }^{10}$ The most important objective of application of filter aids is to make the cake more permeable, by increasing the porosity and reducing the compressibility of the cake, ${ }^{11-13}$ which together help to obtain a higher filtration capacity. In many cases, these improvements in the cake properties also have a positive effect on the residual moisture content of the cakes. The clarity of filtrate can also be enhanced along with the filtration capacity, compared to the situation without filter aids. Because of the factors listed above, which relate to the cake properties and interactions between the filter aid and the original suspension, the selection of a filter aid usually requires experimental work.

Filter aids have been traditionally used in order to improve filtration of beer and food products, ${ }^{14-17}$ and other suspensions where fine or compactible particles are present. ${ }^{18}$ The type and dosage of a filter aid is determined by the aim of the filtration process; the ideal product can be, for instance, a clear liquid or a dry solid fraction. Additionally, simultaneous removal of impurities, e.g. heavy metals, from the liquid by adsorption can also be considered. ${ }^{19}$ For cake filtration, several materials have been recognized to be suitable as filter aids. Forms of diatomaceous earth (diatomite), together with perlite, are the most applied inorganic filter aids in the chemical and process industries. Organic filter aids, suitable for the filtration of bulk products, are mainly composed of cellulose. The inorganic waste fractions, ashes, which are produced when organic materials are burnt, can also be utilized as filter aids. ${ }^{20}$ In addition to these established filter aids, coal preparations, talc, plastics, and synthetic silicates may also be considered. ${ }^{11}$

The objective of this study was to improve the filterability of a cardboard waste suspension after enzymatic hydrolysis performed for bioethanol production. Enzymatic hydrolysis of recycled paper and residual cardboard to produce monomeric sugars have previously been studied by Nazhad et al. ${ }^{21}$, Wang et al. ${ }^{22}$, and Yanez et al. ${ }^{23}$. In this study, a laboratory-scale pressure filter was used in order to investigate the effect of filter aid type, dosage and method of use on the filtration rate and characteristics of the filter cakes. Both organic and inorganic filter aids were used as either precoat or body feed. The filter aid dosage was varied from 10 to $20 \mathrm{wt} . \%$, relative to the corresponding mass of solids present in the hydrolyzed suspension. 


\section{MATERIALS AND METHODS}

\subsection{Enzymatic hydrolysis of cardboard waste}

The enzymatic hydrolysis of shredded cardboard was performed in an agitated vessel with a volume of $300 \mathrm{dm}^{3}$. The cardboard sample mainly consisted of old corrugated cardboard, collected from Finland. An approximate composition of the cardboard was determined, as described by Kinnarinen et al. ${ }^{24}$. The cellulose, hemicellulose, lignin and ash contents were $63,14,12$, and $11 \mathrm{wt} . \%$, respectively. Only one large batch of hydrolysate $\left(170 \mathrm{dm}^{3}\right)$ was produced in order to provide the best possible comparability for the subsequent filtration experiments.

The following materials were used for the batch preparation: 1) shredded cardboard, 2) water, 3) sulfuric acid, 4) cellulase preparation, and 5) hemicellulase preparation. The cardboard was first mixed with water to form a suspension with a total solid (TS) content of $8 \mathrm{wt} . \%$. Two types of commercially-available enzyme preparations were used for converting the solid cellulose and hemicellulose to soluble sugars, at a constant temperature of $46^{\circ} \mathrm{C}$. Both of these products, Cellic CTec 2 and Cellic HTec, were manufactured by Novozymes, Denmark. There was a need for $\mathrm{pH}$ adjustment, because a $\mathrm{pH}$ of 5 was optimal for the enzymes. Sulfuric acid $(2 \mathrm{~mol} / \mathrm{L})$ was slowly added into the mixture to lower the $\mathrm{pH}$ from greater than 7 to 5.0 . The volumes of the cellulase and hemicellulase products added were $1.92 \mathrm{dm}^{3}$ and $0.80 \mathrm{dm}^{3}$, respectively. These volumes correspond to 137 and $57 \mathrm{~mL}$ enzyme $/ \mathrm{kg}_{\text {solids }}$.

During hydrolysis, the mixing rate was relatively slow, $35 \mathrm{rpm}$, because the aim was to avoid deactivation of enzymes and mixing of air bubbles into the suspension. The dimensions of the vessel and the mixing element are shown in Figure 1 a. Initially, the suspension was difficult to mix. However, during the first hour after the enzyme addition, its viscosity was significantly reduced and mixing became easier. The final suspension (Figure $1 \mathrm{~b}$ ) after the hydrolysis was very easy to mix and pump, with the exception of the largest impurities. These impurities, comprising mainly metals and plastics, were removed from the suspension by screening, using a sieve with a mesh size of $4 \mathrm{~mm}$. 


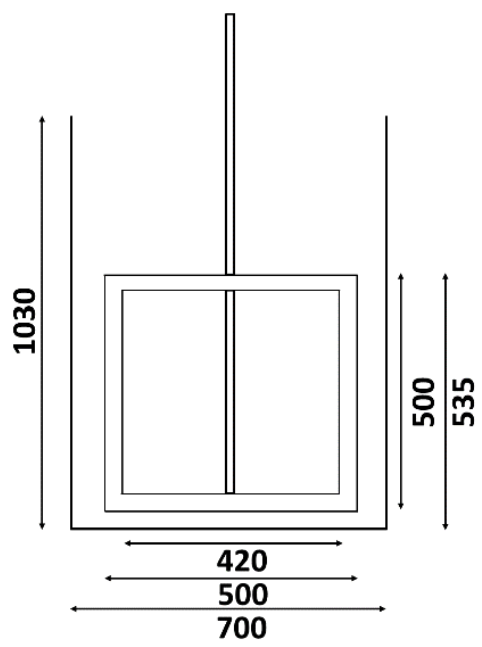

(a)

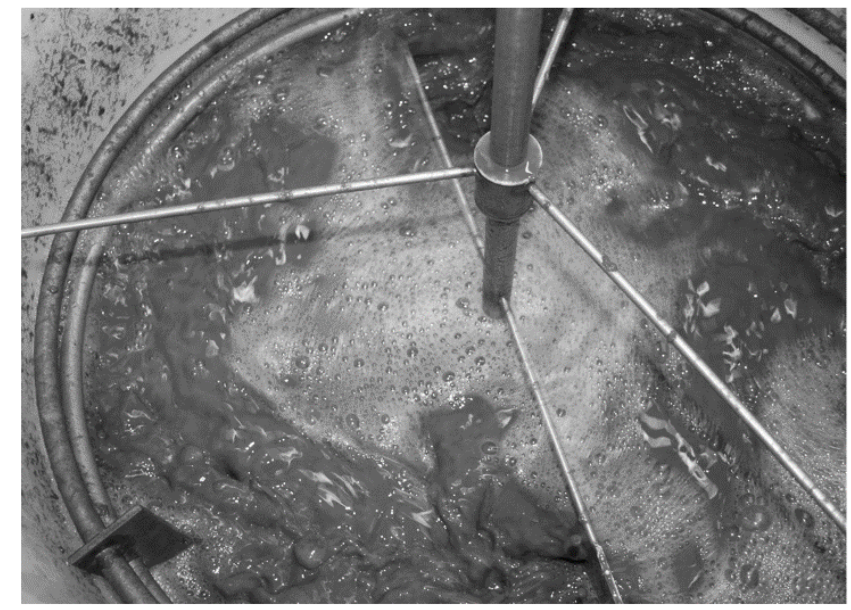

(b)

Figure 1. Dimensions (mm) of the hydrolysis vessel and the mixing element (a). The suspension after 70 hours of enzymatic hydrolysis (b).

After screening, the suspension was again mixed well and divided into several small vessels of $10 \mathrm{dm}^{3}$ that were then stored in a freezer. Prior to each series of experiments, a sufficient amount of slurry was slowly brought to $20-22{ }^{\circ} \mathrm{C}$.

\subsection{Filter aids}

Seven different types of filter aids were investigated. These materials, listed below, varied from cellulosic to inorganic and from traditional to novel.

1. Cellulose EFC-900

2. Diatomaceous earth / diatomite

3. Milled cardboard waste / the hydrolyzed material itself

4. Kenaf fibers

5. Rice hull ash (Standard)

6. Rice hull ash $(\mathrm{X}+100)$

7. Rice hull ash (Grade 4)

An Olympus SZX9 optical microscope (50 x magnification) equipped with a Leica DFC 450 camera was used for physical characterization of the filter aids. Stereomicroscope images of all filter aids are shown in Figure 2 a-g.

The organic filter aids, including cellulose, milled cardboard waste and kenaf, were mainly composed of (broken and intact) cellulosic fibers, while diatomite and the rice hull ashes (RHA) represented particulate inorganic solids of irregular particle shape. The approximate volumetric particle size distributions of all filter aids, measured using a Beckman Coulter LS 
13320 particle size analyzer, are presented in Table 1. A detailed description of the particle size measurement is presented in Section 2.4.

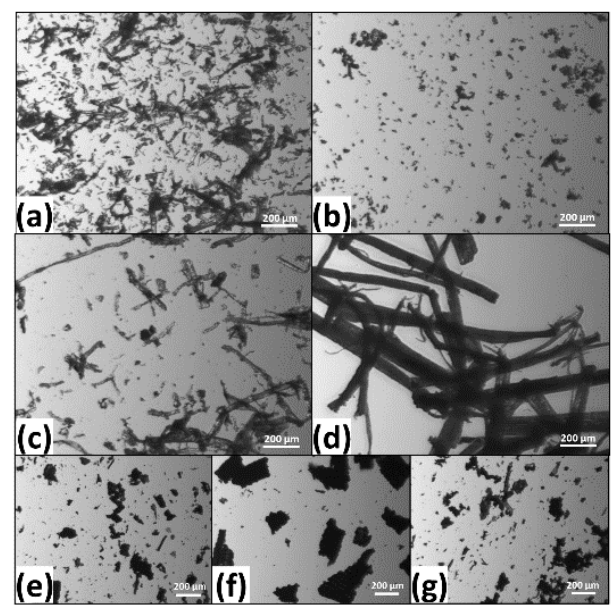

Figure 2. Stereomicroscope images of the filter aids: cellulose (a), diatomite (b), milled cardboard (c), kenaf fibers (d), three grades of rice hull ash; Standard (e), $\mathrm{X}+100$ (f), and Grade 4 (g).

Diatomite, produced by Dicalite/Dicaperl Minerals (Bala Cynwyd, PA, USA), contained the smallest particles, while the rice hull ashes consisted of larger particles, which were of relatively equal size in all three grades used. The particle size of the milled cardboard and, especially, the kenaf fibers were significantly larger than in the case of cellulose. It is important to note that the size distribution determined for fibers is not directly comparable with particulate solids, due to the needle-like shape and totally different structure of the fibers. The analysis technique used for the particle size analysis was based on laser diffraction and the device used assumes the particles to be spherical.

\section{Table 1. Approximate particle size distributions of the filter aids}

\begin{tabular}{llllll}
\hline \multirow{2}{*}{ Filter aid } & \multicolumn{5}{l}{ Particle diameter $(\mu \mathrm{m})$} \\
\cline { 2 - 6 } & $D_{10}$ & $D_{25}$ & $D_{50}$ & $D_{75}$ & $D_{90}$ \\
\hline Diatomite & 2.8 & 8.3 & 18.1 & 32.3 & 49.5 \\
Cellulose & 18.4 & 51.9 & 118.5 & 207.6 & 325.7 \\
Cardboard & 29.4 & 74.1 & 220.3 & 654.5 & 1222.0 \\
Kenaf & 104.7 & 167.1 & 385.6 & 951.7 & 1503.0 \\
RHA (Standard) & 9.3 & 24.7 & 52.7 & 91.4 & 144.4 \\
RHA (X+100) & 10.7 & 30.5 & 69.1 & 132.8 & 188.2 \\
RHA (Grade 4) & 9.0 & 22.9 & 46.7 & 77.7 & 114.4 \\
\hline
\end{tabular}


In this case, shredded cardboard was milled in order to further reduce the particle size. After milling, the maximum particle size of the material was $1.5 \mathrm{~mm}$. The EFC-900 cellulose, a commercial extract-free, non-bleached product, was manufactured by J. Rettenmaier \& Söhne Gmbh (Rosenberg, Germany). The kenaf (Hibiscus cannabinus) sample was supplied by Kenaf USA, LLC (St. Augustine, FL, USA). The kenaf sample was sieved using a pack of several sieves, with mesh sizes between 50 and $355 \mu \mathrm{m}$. From this, one of the most abundant fractions, 100-180 $\mu \mathrm{m}$, was selected as a filter aid for the experiments. Filter aids consisting of cellulosic fibers have some special benefits, such as low density, favorable structure with rough surfaces and high porosity, easy cleaning of filter cloth and good possibilities for disposal or energy production by combustion. ${ }^{25}$

Among the investigated materials, diatomaceous earth (diatomite) is perhaps the most used in the chemical and processing industries. The high porosity and low compressibility of diatomite make it an excellent filter aid for several applications, including related processes, such as beer filtration. ${ }^{14}$ However, there are also some major challenges associated to diatomite, including health hazards, long-distance transportation, regeneration after use, and final disposal. The other inorganic filter aids, different types of rice hull ash, were provided by Agrielectric Research (Lake Charles, LA, USA). The ash grades were obtained from size classification of the same original RHA. Besides particle size, there were variations in particle shape and $\mathrm{pH}$. The largest RHA particles typically had the highest $\mathrm{pH}$ and zeta potential. The smallest particles, on the other hand, had a more irregular shape, which increased the permeability. Rice hull ash is the final waste produced when rice hulls, the nonfood part covering rice grains, are burned. It is high in silica content and provides a high porosity when used as a filter aid. Rice hull ash, as with many other types of ashes, could also be used for concrete and brick manufacture, soil amelioration or as an adsorbent, to mention just a few potential applications. ${ }^{26}$ There are several factors that affect the performance of rice hull ash in filtration applications, including the chemical composition, physical structure and properties, and characteristics related to the particle size and shape. ${ }^{20}$

\subsection{Filtration experiments}

In the filtration experiments, a laboratory scale pressure filter was used. The filter unit, Labox 100, was designed by Outotec Oy, Finland. The main parts of the filter are shown in Figure 3. The pump attached to the equipment can be seen behind the pressure gauge next to the slurry inlet. Based on preliminary tests, AINO T70 cloth, also supplied by Outotec Oy, was selected as the filter cloth. The cloth material was polypropylene and the air permeability of the cloth was $15 \mathrm{~m}^{3} \mathrm{~m}^{-2} \mathrm{~min}^{-1}$. The height of the filter chamber was adjustable, but was kept constant (at $33 \mathrm{~mm}$ ) throughout the study. In the top of the filter chamber, there was an elastic diaphragm that was inflated with compressed air to perform cake squeezing. Additionally, the experimental arrangement included a mixing tank $\left(V=20 \mathrm{dm}^{3}\right)$ for the slurry and a small $\left(3 \mathrm{dm}^{3}\right)$ mixing tank for mixing the suspensions consisting of water and the precoat filter aids. The small mixing tank was also used when the pre-determined amount of slurry was mixed with a certain mass of filter aids for the body feed tests. The filtration parameters were selected based on the results of a preliminary series of experiments. A simple filtration cycle 
was selected, comprising only pumping at 4 bar for 10 min and cake pressing at 10 bar for 4 min, in order to produce completely saturated filter cakes. All filtration experiments were carried out at room temperature $\left(22^{\circ} \mathrm{C}\right)$.

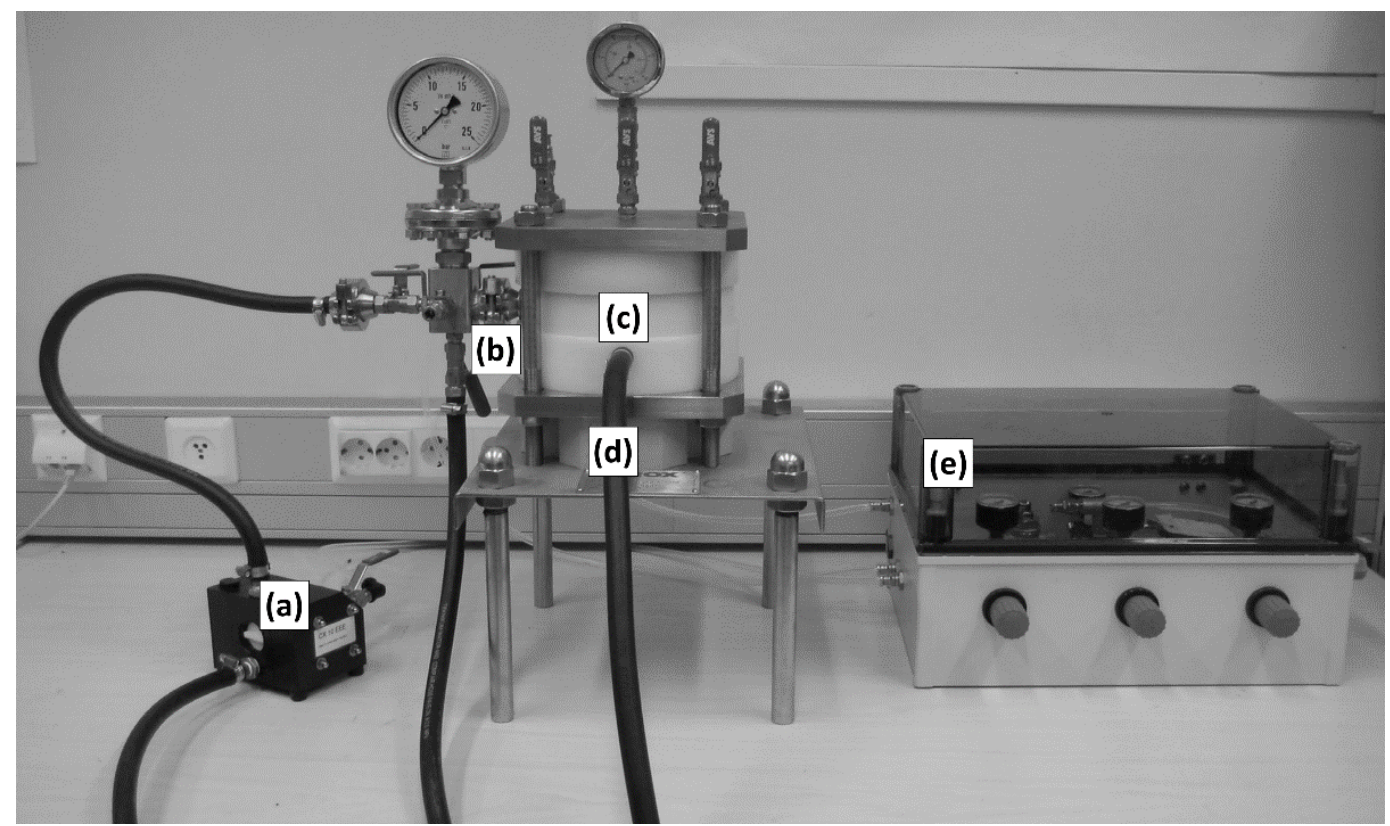

Figure 3. Labox 100 filter press. Feed pump (a), slurry inlet (b), filter chamber (c), filtrate outlet (d), and the pressure control unit (e).

The experimental study consisted of two parts, where the selected filter aids were used for improving the filterability of the biomass hydrolysate, using (i) precoat and (ii) body feed modes. In addition to the method of using filter aids, the relative amount of the filter aids was varied. Concentrations of 10 and $20 \mathrm{wt} . \%$, relative to the amount of total solids (TS) in the slurry, were used. When the filter aids were applied using the precoat mode, the filter aid was first slurried with water and this suspension was then filtered at low pressure (1 bar) to form the precoat cake on the filter cloth. In this case, excess water was removed from the cake by pressing it, at 2 bar, for 2 minutes.

\subsection{Measurements and calculations}

The final concentrations of the main sugars, glucose and xylose, were determined by highperformance liquid chromatography (HPLC). An HP Agilent 1100 was used, equipped with a Varian Metacarb $87 \mathrm{H}$ column that was kept at $60.0^{\circ} \mathrm{C}$. The eluent was $0.005 \mathrm{M}$ sulfuric acid. The pumping rate and the injection volume were $0.6 \mathrm{~mL} / \mathrm{min}$ and $10 \mu \mathrm{L}$, respectively.

Determination of total solids (TS) in the slurry and filtrate was performed by drying in a heating chamber at $105^{\circ} \mathrm{C}$ until a constant weight was reached. The moisture content of the filter cakes was determined using the same procedure. 
Particle size distributions (PSD) of the filter aids were measured using a Beckman Coulter LS 13320 laser diffraction analyzer with the Fraunhofer optical model and an aqueous liquid module. After careful sampling, a small amount of each filter aid was suspended in water and a small sample from this suspension taken for the PSD analysis. Each sample was analyzed 6 times and provided none of the PSDs significantly differed from the others, the distributions were averaged. If significant differences were observed, another sample of the same filter aid was analyzed 6 times and then averaged.

The filtration capacities $\left(\mathrm{kg} /\left(\mathrm{m}^{2} \mathrm{~h}\right)\right)$, with respect to dry solids, were calculated as gross capacities, omitting the technical time that is associated with opening, closing, cake discharge, cloth washing, and other such necessary operations in a full-scale filter. Calculation of the average specific cake resistance $(\mathrm{m} / \mathrm{kg})$ is presented in Section 3 .

\section{THEORY}

The theory of cake filtration is derived from Darcy's law, which deals with flow of fluid through a porous medium. The driving force in cake filtration is the pressure drop $\Delta p(\mathrm{~Pa})$ through the medium, which in this case includes both the cake and the filter cloth. As a result of the driving force, the liquid is forced to flow in the direction of the decreasing hydraulic pressure gradient. Regarding the packing of solid particles in the cake, the minimum porosity (the volume ratio of the non-solid to the total) is found at the filter medium and the maximum on the top of the cake. ${ }^{27}$ For constant pressure filtration, the filtrate flow rate $Q\left(\mathrm{~m}^{3} / \mathrm{s}\right)$ through the cake and the filter medium can be calculated from Eq. (1).

$Q=\frac{A \Delta p}{\mu\left(R+R_{C}\right)}$

Where $A\left(\mathrm{~m}^{2}\right)$ is the filtration area, $\mu$ (Pa s) is the viscosity of the filtrate, and the resistances of the medium and the cake are $R$ and $R_{c}(1 / \mathrm{m})$, respectively. Usually the medium resistance, caused by the filter medium and the solid particles that interact with it, is assumed to be constant, whereas the cake resistance increases with cake growth. Therefore, the amount of cake formed per filtration area from slurry with a solid concentration $c\left(\mathrm{~kg}_{\text {solids }} / \mathrm{m}^{3}\right.$ filtrate), when a filtrate volume $V\left(\mathrm{~m}^{3}\right)$ is collected, must be taken into account. Then Eq. (1) becomes:

$Q=\frac{A \Delta p}{\alpha \mu c \frac{V}{A}+\mu R}$

Where $\alpha(\mathrm{m} / \mathrm{kg})$ is the specific cake resistance.

The reciprocal form of Eq. (2) presents the separate terms for the specific cake resistance and the resistance of the filter medium:

$\frac{d t}{d V}=\frac{\alpha \mu c}{A^{2} \Delta p} V+\frac{\mu R}{A \Delta p}$ 
After integration, starting from the beginning of the constant pressure period $\left(t_{s}, V_{s}\right)$, Eq. (3) finally becomes:

$\frac{t-t_{s}}{V-V_{s}}=\frac{\alpha \mu c}{2 A^{2} \Delta p}\left(V+V_{s}\right)+\frac{\mu R}{A \Delta p}$

In experimental filtration studies, the average specific cake resistance $\alpha_{a v}(\mathrm{~m} / \mathrm{kg})$ and the medium resistance $R$ can be calculated from the collected data of constant pressure filtration using the slopes $a\left(\mathrm{~s} / \mathrm{m}^{6}\right)$ and $b(\mathrm{~s} / \mathrm{m})$ obtained from $t / V$ against $V$ plots ${ }^{24}$. These plots are created based on the filtrate volume collected in time $t$. The final equations for constant pressure filtration are then

$\alpha_{a v}=\frac{a 2 A^{2} \Delta p}{\mu c}$

$R=\frac{A \Delta p b}{\mu}$

The equations presented above can be used to evaluate cake filtration in applications, where local differences in the cake structure are not considered. The above equations and a precise introduction on the theory of constant pressure filtration have been presented, among others, by Svarovsky ${ }^{28}$ and Gösele ${ }^{29}$. The motion of solids in the cake is assumed to be negligible and the specific cake resistance for certain slurry is assumed to depend only on the compressive stress. ${ }^{30}$ In practice, determination of average specific cake resistance can be very time-consuming. Therefore, methods to simplify the determination of $\alpha_{a v}$ have been proposed, for instance, by Teoh et al., ${ }^{31}$ who used instantaneous filtration rates for the calculation of $\alpha_{a v}$. The main drawback of this method is that accurate estimation of the instantaneous filtration velocities is difficult and may lead to poor repeatability. In this study, all moments of filtration were considered when the average specific cake resistances were calculated.

An important measure of the success of separation, the liquid recovery as filtrate, $R_{l}$, was calculated from Eq. (7):

$R_{l}=\frac{m_{\text {liquid,filtrate }}}{m_{\text {liquid,filtrate }}+m_{\text {liquid,cake }}}$

\section{RESULTS AND DISCUSSION}

The results obtained using filter aids were compared with the case without filter aids. The filterability was evaluated with the help of filtrate accumulation curves and the average specific cake resistances obtained.

\subsection{Filtration curves}


The body feed experiments were performed using all available filter aids. Because of technical problems with pumping the long and high-frictional kenaf fibers, these were excluded from the precoat experiments.

The performance of the filter aids in body feed and precoat filtration of the biomass hydrolysate can be evaluated based on Figures 4 and 5. As illustrated in Figure 4, all filter aids helped to enhance filterability when the body feed mode was used. In this case, organic filter aids (Figure 4 a) were observed to be less effective than diatomite, which increased the average filtration rate during the pumping stage by $75 \%$ compared to the case without filter aid. However, the milled cardboard waste would possibly be the most economical option for the studied process, because it is always available from the raw material. The superior performance of diatomite at $20 \mathrm{wt} . \%$ concentration could partially result from the higher compressibility of the organic filter aid materials. Moreover, the dosing of the filter aids was mass-based, so the volume of organic filter aids pumped into the filter was significantly larger. This may have caused an excessively dense structure of the filter cake already during the filtration stage.

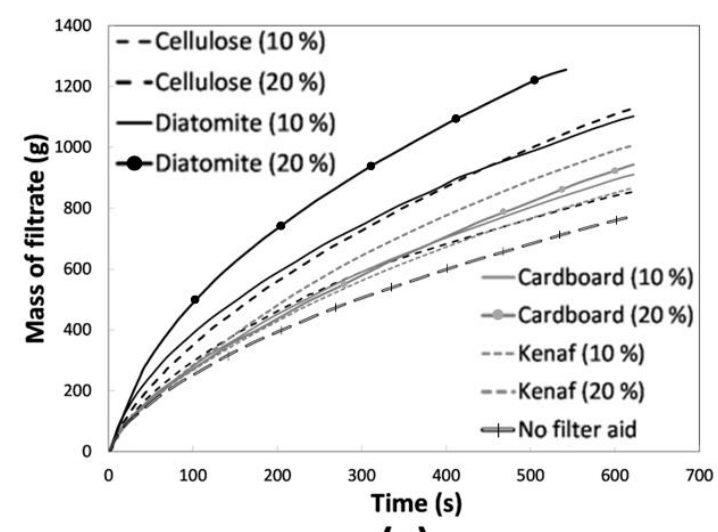

(a)

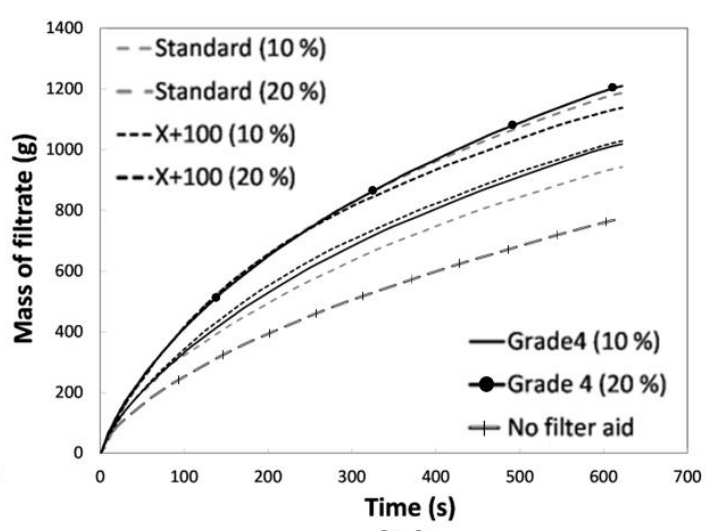

(b)

Figure 4. Accumulation of filtrate during pressure filtration at 4 bar: Body feed mode using cellulose, diatomite, cardboard and kenaf (a); body feed mode using various types of rice hull ash (b).

The differences in the performance of the rice hull ashes (Figure $4 \mathrm{~b}$ ) were smaller. During the filtration time of $600 \mathrm{~s}$, the amount of filtrate collected was increased by $57 \%$ in the best case (RHA Grade 4). As shown above in Table 1, the particle size distribution implies that this RHA is composed of the finest particles, in comparison with the other RHA products. Irrespective of the filter aid, the increase in the accumulation rate of filtrate was clear when the filter aid consumption was increased from 10 to $20 \mathrm{wt} . \%$.

There was only a slight improvement in the filterability as a result of precoat addition (Figure $5 \mathrm{a}-\mathrm{b})$. The maximum increase in the quantity of filtrate collected was only $10 \%$ for cellulose and diatomite, and 10-21\% for the different grades of RHAs. It can be assumed that the precoat layer forms an independent filter medium, on which the filter cake is formed. The liquid permeability of the precoat layer varies depending on the type of filter aid and the 
precoating conditions. These factors may also affect the ability of the precoat layer to retain solid particles. It is apparent that the filter aid dosage should not be too high, because, after a certain point, the resistance caused by the increasing cake thickness surpasses the benefits.

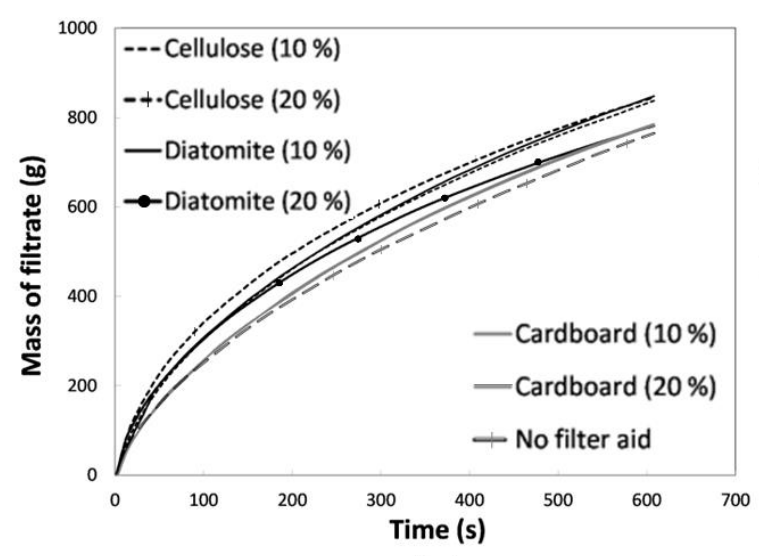

(a)

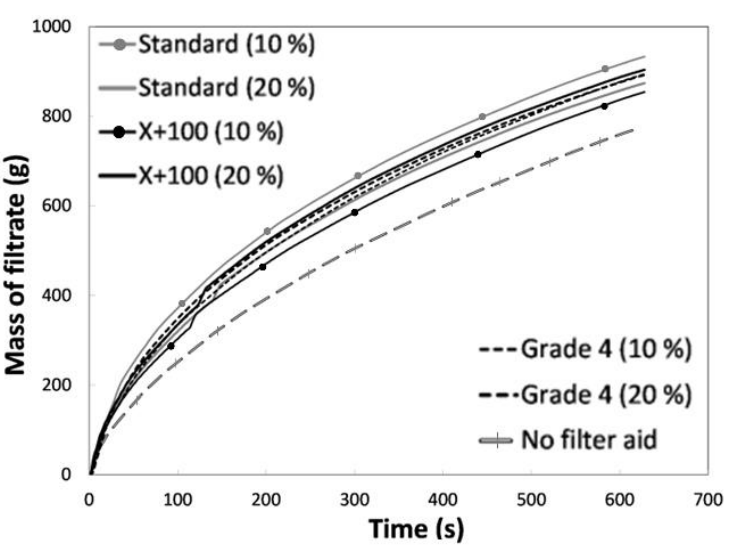

(b)

Figure 5. Accumulation of filtrate during pressure filtration at 4 bar: precoat mode using cellulose, diatomite and cardboard (a); precoat mode using various types of rice hull ash (b).

The differences between the precoat results vere smaller than in the case of body feed. Further, the filter aid dosage did not have a clear influence on the filtrate flow rate. These results are most likely due to the high filtration resistance of the biomass suspension, which is, in all cases, clearly higher than the resistance caused by any of the filter aids. Based on observations made during the experiments, flocculation of solids did not occur during the process.

With respect to the retention of suspended solids, precoat was excellent in all cases. The average total solid (TS) contents in the body feed and precoat filtrates were 4.9 and $4.6 \mathrm{wt} . \%$, respectively. The precoat filtrates were practically free of suspended solids, whereas the body feed filtrates were turbid, containing both colloidal and settleable matter. The clarity of filtrate did not depend on the type of filter aid used.

However, it may be possible to improve the separation performance by selecting a filter aid that has an opposite surface charge to the particles present in the hydrolysate under process conditions, in order to reduce the electrical repulsion between particles and fibers. The surface charge of cellulose fibers and most inorganic minerals, including the silica-based diatomite and rice hull ash, is net negative at the $\mathrm{pH}$ of the process. When the surface charge of the solids is low enough, attractive van der Waals forces dominate the particle-particle interactions and flocculation can take place. Flocculation of solids, and in particular colloids, occurring as a result of reduced electrical repulsion can be assumed to improve the separation process. This is not only with respect to enhanced clarity of the filtrate, but also cake production capacity. 
Varghese and Cleveland ${ }^{32}$ used kenaf as a body feed filter aid. They compared the performance of kenaf with commercial filter aids (diatomite, perlite, Solkafloc) by filtering a dilute $(1 \%)$ kaolin suspension and obtained a significant improvement in the filtration rate in all cases. They concluded that the filter area requirement using kenaf was about 25-30\% larger than that required when commercial filter aids were used. In the case of kenaf, the filtrate turbidities were also at a high level, compared to diatomite and perlite. In addition to kenaf fibers, kenaf core has also been successfully used as a filter aid. ${ }^{33}$ Carman $^{13}$ investigated the suitability of diatomite as a filter aid for fine metal hydroxides. He concluded that the mechanical action of the filter aid was mainly responsible for the improved permeability of the filter cakes. Li et al. ${ }^{17}$ observed that filtration rate of wastewater sludge could be greatly increased by the addition of rice hull ash (RHA). Depending on the origin of the sludge, the relative increase in the dewatering rate varied from 7 to $45 \%$ with a $50 \%$ RHA dosage and from 2 to $14 \%$ with a $10 \%$ RHA dosage. The filtrate quality (color) and the cake dryness were also significantly improved. With respect to diatomite, Carman ${ }^{13}$ concluded that the positive influence of diatomite addition is not only due to the increased porosity: the rigid structure of the cake and the surface properties of diatomite particles contribute to the filtration rate and the quality of the filtrate. The benefits of organic filter aids, such as refined cellulose products, have been earlier discussed by Gerdes. ${ }^{25}$ Regarding the disposal, combustion or reuse in certain situations, organic filter aids may have an advantage, as discussed later in Section 4.4.

It is possible that the filter aid dosages used in this study were higher or lower than the optimum dosage of the filter aids. Therefore, the performance of a single type of filter aid should not be generalized. Further, the results are process specific, which means that small changes in the $\mathrm{pH}$, temperature, solid contents, etc. may either improve or decrease the performance of a filter aid.

\subsection{Specific cake resistance, cake moisture and filtration capacity}

The average specific cake resistances for the slurry without filter aid and for all precoat experiments are illustrated in Figure 6 a. In most cases, the reduction in $\alpha_{a v}$ is quite poor. It is apparent that precoat is not the most favorable feeding strategy for a pressure filter, since none of the filter aids worked especially well. 


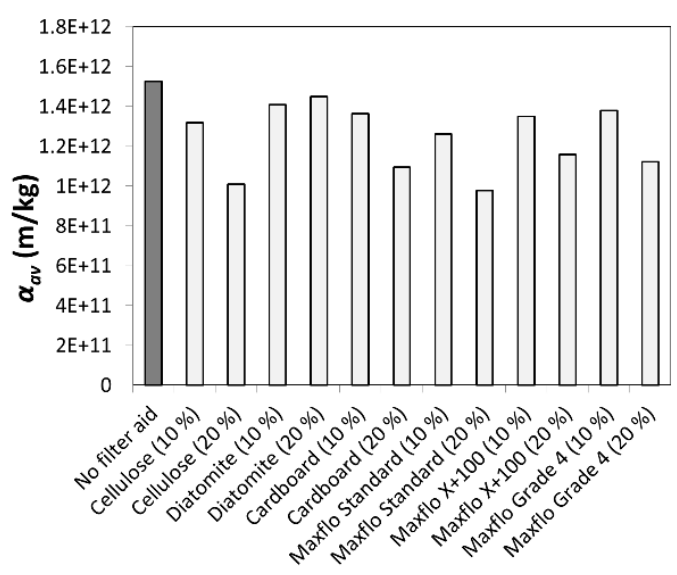

(a)

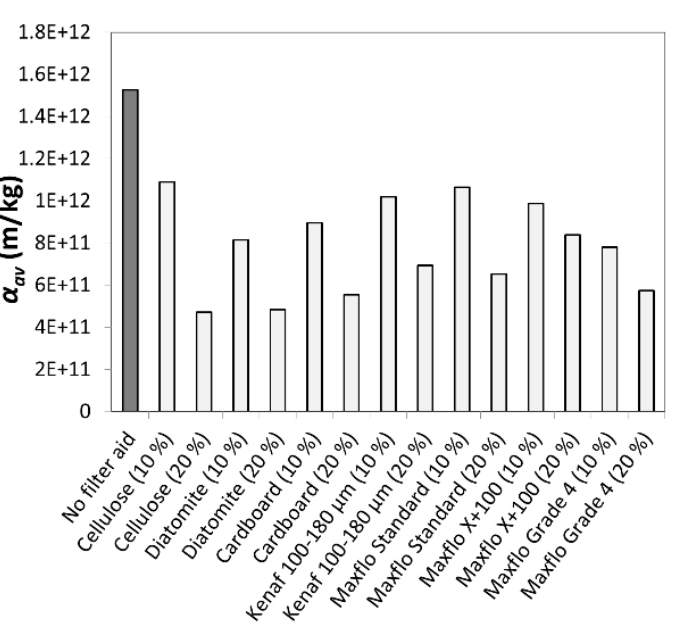

(b)

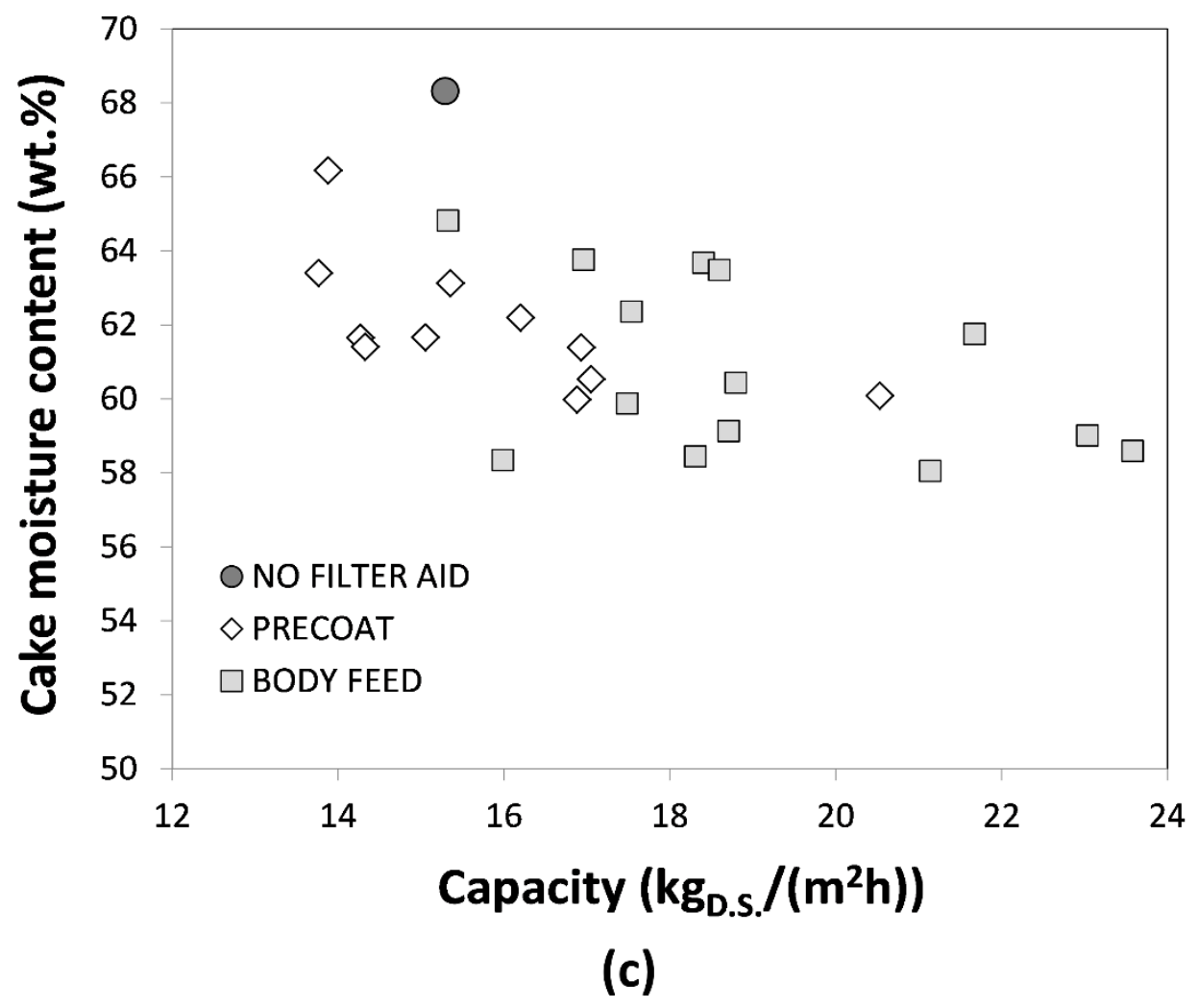

Figure 6. The average specific cake resistance $\alpha_{a v}$ obtained using the precoat (a) and body feed (b) modes. Moisture contents of the filter cakes plotted against filtration capacities obtained using the precoat and body feed modes (c).

As Figure $6 \mathrm{~b}$ shows, the same amounts of filter aids that were used in the precoat experiments are enough to produce a significantly reduced $\alpha_{a v}$ when the body feed mode is applied. Unlike 
in the case of the precoat mode, the amount of the filter aid had a clear influence on $\alpha_{a v}$. This influence was of different magnitude for each filter aid, but $\alpha_{a v}$ was, without exception, reduced as the filter aid concentration was increased. There are a number of reasons for the good performance of the body feed mode: 1) open cake structure that reduced the flow resistance, 2) rigid cake structure that reduced the compressibility, and 3) the inclusion of all filter aid particles in the cake, not below the cake or in the pores of the filter cloth. After all, considering the aspect of the complete filtration cycle, body feed clearly seems to be the recommended feeding strategy for pressure filters. This filter aid feeding strategy reduces the total cycle time and simplifies the process.

The repeatability of the filtration experiments was evaluated by performing two parallel trials for selected body feed and precoat experiments. Cardboard and Maxflo Standard were used, at a concentration of $20 \mathrm{wt} . \%$. The mass of filtrate collected during the pumping stage did not vary dramatically: the minimum variation from the average was $\pm 0.5 \%$ in the case of cardboard / body feed and the maximum was $\pm 2.2 \%$ in the case of Maxflo Standard / precoat. In the case of cardboard / precoat and Maxflo Standard / body feed, the variations were \pm 1.0 and $\pm 1.2 \%$, respectively. Because the pressure control was performed manually, it is apparent that the inaccuracy of pressure control in the pumping stage was the most important source of this variation.

These results also imply that the performance of the filter medium was successfully restored by washing the filter medium with water after each experiment. In other words, there was no serious pore blockage. The relatively open pore structure of the filter medium apparently facilitated the effectiveness of the cloth washing.

Figure $6 \mathrm{c}$ presents the obtained filtration capacities and the corresponding moisture contents of the cakes after the filtration and cake pressing stages. It can be observed in Figure $6 \mathrm{c}$ that the successful use of filter aids, irrespective of the mode of addition, helps to increase the filtration capacity and to reduce the cake moisture content. The moisture content was reduced in all cases, while the capacity could not be improved in a few precoat experiments. The recovery of liquid within the filtrate (Eq. 7) varied from 91.4 to $94.7 \%$, in the case of body feed, and from 91.0 to 94.0 in the case of precoat (Table 2).

Table 2. Liquid recovery within the filtrate.

\begin{tabular}{lllllll}
\hline Filtration mode & \multicolumn{3}{l}{ Liquid recovery $(\%)$} & & Standard deviation & \\
\cline { 2 - 3 } \cline { 6 - 7 } & Aver. & Min. & Max. & & Absolute (\%-units) & Relative (\%) \\
\hline Body feed $(\mathrm{n}=14)$ & 93.2 & 91.4 & 94.7 & & 1.0 & 1.1 \\
Precoat $(\mathrm{n}=12)$ & 92.6 & 91.0 & 94.0 & & 0.9 & 1.0 \\
\hline
\end{tabular}

Modeling of the average specific cake resistance for a binary mixture containing filter aids and the material to be filtered has been carried out by Abe et al. ${ }^{34}$ They used KozenyCarman's equation as a basis for two models, which in turn were based on the assumption of complete mixing and segregation of particles. The assumption of complete mixing was 
shown to be valid for non-spherical particles, whereas segregation phenomena had an important role in the case of spherical particles of significantly different sizes.

The compressibility of filter cakes under pressure can also be reduced using filter aids. In the case of compressible cakes, specific cake resistance increases with filtration pressure. The compressibility index $n$ (not determined in this study) can be determined using an empirical relationship $\alpha=\alpha_{0} \Delta p^{n}$, as presented by Svarovsky ${ }^{28}$. During the pressing stage, consolidation of the filter cake is sometimes divided into two different types: 1) primary, which involves removal of liquid from the pores and the resulting reduction in the height of the cake and 2) secondary, which stands for rearrangement of particles and creep of the solid structure. In the present study, both types of consolidation probably occurred, although precise evaluation of the consolidation was not possible, due to the configuration of the filter unit. Li et al.$^{35}$ mixed rice hull ash with super-compactible wastewater sludge and obtained a significant reduction in the cake compressibility. The compressibility index $n$ was reduced from the supercompactible 1.13 to a moderately compactible 0.4 . The filtration rates and the solid contents of the cakes were consequently increased.

In the case of very compressible cakes that have exceptionally high average specific resistances, it is possible that the addition of filter aids alone cannot reduce the resistance to filtration sufficiently to enable feasible operation. Moreover, the specific filter aid requirement can have a significant effect on the process economy. There are, fortunately, other methods that can be used together with filter aids. Polymeric flocculation, preconcentration of the feed suspension, and filtration at elevated temperature, for instance, could help to increase the productivity.

\subsection{Effect of filter cloth on the quality of filtrate}

The filter cloth is usually regarded as the most important component of a filter. The purpose of the filter cloth is to capture the suspended particles, to provide a support layer for cake growth and to permit a high flow of filtrate. In this study, three polypropylene filter cloths (AINO K10, T32 and T70) were evaluated with respect to the filtration resistance and the turbidity of filtrates, as shown in Figure 7. The main difference between the selected filter cloths was the pore size distribution and, consequently, permeability. 


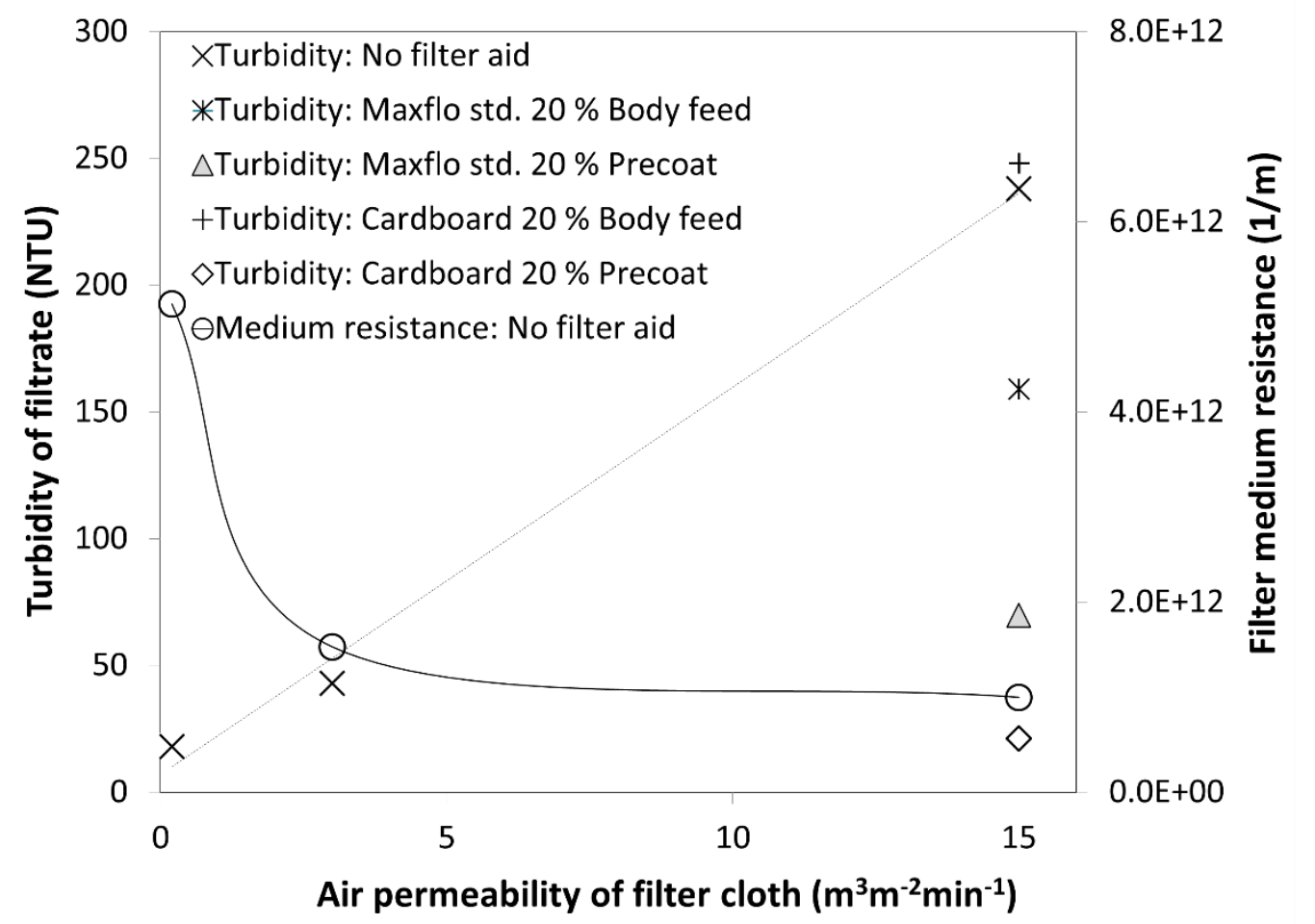

Figure 7. Turbidity of filtrate obtained using three different polypropylene filter cloths, having air permeabilities of $0.2,3$ and $15 \mathrm{~m}^{3} \mathrm{~m}^{-2} \mathrm{~min}^{-1}$, according to the manufacturer (Outotec Oy, Finland). The experimentally determined resistances of the filter media (Eq. 6) are also shown.

As illustrated in Figure 7, the filter cloth has a significant influence on the turbidity of the filtrate. However, the resistance of the least permeable filter cloth is relatively high. It is, therefore, important to select a filter cloth, which is able to fulfill the requirements regarding both permeability and the degree of filtrate turbidity. It is also clear from Figure 7 that the filtrate turbidity cannot be substantially reduced using body feed mode. The difference between the average total solid concentrations of the body feed and precoat filtrates, 4.9 and 4.6 wt.\% (Section 4.1), represent the amount of fine solids that cause this increase in the turbidity.

\subsection{Alternatives for filter aid reuse and utilization}

The material efficiency of a filtration process can be improved by recycling the digestible fiber back to the enzymatic hydrolysis and by reusing the non-digestible inorganic matter as a filter aid. The process sketch presented in Figure 8 is quite simplified and may require some additional process units to be effective in practice. In Figure 8, the hydrolysate is filtered using a pressure filter and the filtrate (a) is recovered for subsequent processing, to be converted to bioethanol. A suggestion for the utilization of the cake, in the case of organic (cellulosic) filter aids, is presented on the left in Figure 8. On the other hand, the reuse of inorganic filter aids is illustrated on the right. The incoming fresh materials in the former 
case include the materials required in the hydrolysis stage and the fresh filter aid. In the latter case, the addition of fresh water, as well as the above-mentioned materials, is necessary for the filter aid reuse in the same process.

It is clear to see from Figure 8 that organic filter aids can be more readily reused. However, it is probable that the non-digestible constituents of lignocellulosic biomass, i.e. lignin and minerals, will concentrate in the process over time and have a negative effect on the hydrolysis and the subsequent filtration. Therefore, these constituents should be either separated or removed (b) from the circuit with the associated digestible fiber. The fiber-rich fraction, or part of the cake, can then be recirculated (e) to the process.

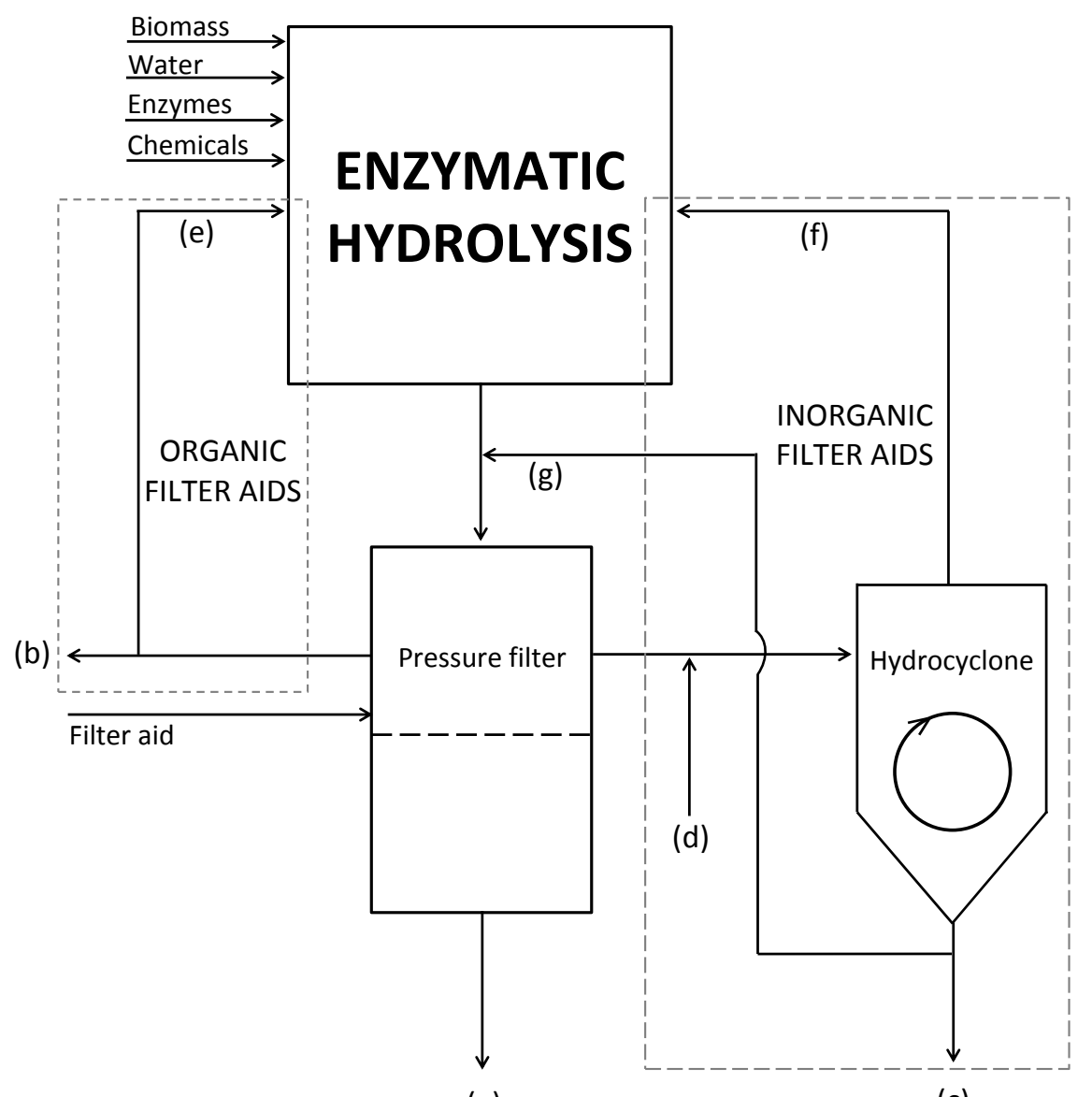

(a)

(c)

Figure 8. Alternatives for the recycling and utilization of organic and inorganic filter aids: (a) filtrate to the next process stage, (b) cake fraction to combustion, (c) spent inorganic filter aids to landfill, (d) fresh water, (e) filter cake recirculated to hydrolysis, (f) cake and water recirculated to hydrolysis, and (g) inorganic filter aids recirculated to the filter.

The reuse of inorganic filter aids requires at least one separation stage. This separation stage requires a certain amount of fresh water (d), but is likely to be easy to perform due to the 
large density difference between the biomass residue $\left(\rho<1100 \mathrm{~kg} / \mathrm{m}^{3}\right)$ and the filter aid $(\rho>$ $\left.2000 \mathrm{~kg} / \mathrm{m}^{3}\right)$. Hydrocyclones, centrifuges, and perhaps also sedimentation tanks could be applied. However, a prerequisite for successful separation is that the cakes can be readily dispersed in water. The filter aids should be returned to the filter at a relatively low moisture content, which means that water should be removed from stream (g). This could be accomplished by a gravity thickener, the water overflow of which could be utilized in the hydrolysis stage, together with stream (f). Part of the used filter aid (c) can also be removed from the process and sent to landfill. If the reuse of filter aid is not of interest, then the filter cake, including the inorganic filter aid, can be landfilled or considered for combustion, although the high mineral content may impair the combustibility in practice.

\section{CONCLUSIONS}

The purpose of this study was to improve the filtration of enzymatically hydrolyzed biomass suspensions using inorganic and organic filter aids. It was shown that various filter aids can be successfully applied to improve the filterability of a hydrolyzed lignocellulosic biomass suspension using a pressure filter. However, further research is needed to optimize the filter aid dosage. The use of the body feed strategy simplifies the process and should be used with pressure filtration when some turbidity in the filtrate can be accepted. Based on the findings, the precoat strategy is not recommended, because the poorly permeable structure of the biomass cake remains unchanged. It is clear that filter aids not only increase the production rate, but also help to reduce the cake moisture. These effects are closely related to the increased porosity and rigidity of the filter cake. The selection between organic and inorganic filter aids depends upon the reuse and utilization of the filter aids and the cake. In order to minimize unnecessary waste disposal, future studies could investigate the utilization of these solids from technical and economical points of view.

\section{AUTHOR INFORMATION}

Corresponding author

*E-mail: teemu.kinnarinen@1ut.fi

Tel.: +358405621398

Notes

The authors declare no competing financial interest.

\section{REFERENCES}

(1) Mooney, C.A.; Mansfield, S.D.; Beatson, R.P.; Saddler, J.N. The Effect of Fiber Characteristics on Hydrolysis and Cellulase Accessibility to Softwood Substrates. Enzyme Microb. Technol. 1999, 25, 644.

(2) Larsen, J.; Haven, M. Ø.; Thirup, L. Inbicon Makes Lignocellulosic Ethanol a Commercial Reality. Biomass Bioenergy. 2012, 46, 36.

(3) Mansfield, S.D.; Mooney, C.; Saddler, J.N. Substrate and Enzyme Characteristics that Limit Cellulose Hydrolysis. Biotechnol. Prog. 1999, 15, 804. 
(4) Balat, M.; Balat, H.; Öz, C. Progress in Bioethanol Processing. Prog. Energy Combust. Sci. 2008, 34, 551.

(5) Cardona, C.A.; Sanchez, O.J. Fuel Ethanol Production: Process Design Trends and Integration Opportunities. Bioresour. Technol. 2007, 98, 2415.

(6) Hamelinck, C.N.; van Hooijdonk, G.; Faaij, A.P.C. Ethanol from Lignocellulosic Biomass: Techno-economic Performance in Short-, Middle- and Long-term. Biomass Bioenergy. 2005, 28, 384.

(7) Huang, H.; Ramaswamy, S.; Tschirner, U.; Ramarao, B.V. A Review of Separation Technologies in Current and Future Biorefineries. Sep. Purif. Technol. 2008, 62, 1.

(8) Kochergin, V.; Miller, K. Evaluation of Target Efficiencies for Solid-liquid Separation Steps in Biofuels Production. Appl. Biochem. Biotechnol. 2011, 163, 90.

(9) Malinovskaya, T.A.; Naidorf, L.S. How to Determine Specific Cake Resistance in Filtering Slurries. Translated from Khim. Neft. Mashinostr. 1965, 6, 26.

(10) Burke, D.R.; Anderson, J.; Gilcrease, P.C.; Menkhaus, T.J. Enhanced Solid-liquid Clarification of Lignocellulosic Slurries using Polyelectrolyte Flocculating Agents. Biomass Bioenergy. 2011, 35, 391.

(11) Alt, C. Filtration. In Ullmann's Encyclopedia of Industrial Chemistry, Electronic Release; Wiley-VCH, Weinheim, 2005.

(12) Cummins, A.B. Clarifying Efficiency of Diatomaceous Filter Aids. Ind. Eng. Chem. 1942, 34(4), 403.

(13) Carman, P.C. The Action of Filter Aids. Ind. Eng. Chem. 1938, 30(10), 1163.

(14) Braun, F.; Hildebrand, N.; Wilkinson, S.; Back, W.; Krottenthaler, M.; Becker, T. Large-scale Study on Beer Filtration with Combined Filter Aid Additions to Cellulose Fibres. J. Inst. Brew. 2011, 117(3), 314.

(15) Sulpizio, T.E. Advances in filter aid and precoat filtration technology. American Filtration \& Separations Society Annual Technical Conference, April 6-9, 1999, Boston, Massachusetts.

(16) Qi, Y.; Thapa, K.B.; Hoadley, A.F.A. Application of Filtration Aids for Improving Sludge Dewatering Properties - a Review. Chem. Eng. J. 2011, 171, 373.

(17) Li, W.; Kiser, C.; Richard, Q. Applications of rice hull ash filter aids in bio-sludge deliquoring. AIChE Spring National Meeting, April 23-27, 2006a, Orlardo, Florida.

(18) Du, L.; Chem, X.; Li, W.; Zhu, Q. A Study on Enhancement of Filtration Process with Filter Aids Diatomaceous Earth and Wood Pulp Cellulose. Chin. J. Chem. Eng. 2011, 19(5), 792.

(19) Irani, M.; Amjadi, M.; Mousavian, M.A. Comparative Study of Lead Sorption onto Natural Perlite, Dolomite and Diatomite. Chem. Eng. J. 2011, 178, 317.

(20) Li, W.; Kiser, C.; Richard, Q. Quality test of rice hull ash filter aids. American Filtration \& Separations Society 2005 International Topical Conferences \& Exposition, September 19-22, 2005, Ann Arbor, Michigan.

(21) Nazhad, M.M.; Ramos, L.P.; Paszner, L.; Saddler, J.N. Structural Constraints Affecting the Initial Enzymatic Hydrolysis of Recycled Paper. Enzyme Microb. Technol. 1995, $17,68$.

(22) Wang, L.; Templer, R.; Murphy, R.J. High-solids Loading Enzymatic Hydrolysis of Waste Papers for Biofuel Production. Appl. Energy. 2012, 99, 23. 
(23) Yanez, R.; Alonso, J.L.; Parajo, J.C. Production of Hemicellulosic Sugars and Glucose from Residual Corrugated Cardboard. Process Biochem. 2004, 39, 1543.

(24) Kinnarinen, T.; Huhtanen, M.; Häkkinen, A.; Louhi-Kultanen, M. Solid-liquid Separation of Hydrolysates Obtained from Enzymatic Hydrolysis of Cardboard Waste. Ind. Crops Prod. 2012, 38(1), 72.

(25) Gerdes, E. Precoat Filtration with Organic Filter Aids. Filtr. Sep. 1997, 34(10), 1040.

(26) Foo, K.Y.; Hameed, B.H. Utilization of Rice Husk Ash as Novel Adsorbent: a Judicious Recycling of the Colloidal Agricultural Waste. Adv. Colloid Interface Sci. 2009, 152, 39.

(27) Tiller, F.M. What the Filter Man Should Know about Theory. Filtration. 2004, (Special Issue) April, 55.

(28) Svarovsky, L. Solid-liquid separation; second ed., Butterworth \& Co, Witham, Essex, 1981.

(29) Gösele, W. Filtration . In Ullmann's Encyclopedia of Industrial Chemistry, Electronic Release; Wiley-VCH, Weinheim, 2005.

(30) Tien, C.; Bai, R. An Assessment of the Conventional Filtration Theory. Chem. Eng. Sci. 2003, 58, 1323.

(31) Teoh, S.; Tan, R.B.H.; Tien, C. A New Procedure for Determining Specific Filter Cake Resistance from Filtration Data. Chem. Eng. Sci. 2006, 61, 4957.

(32) Varghese, B.K.; Cleveland, T.G. Kenaf as a Body-feed Filter Aid. Adv. Filtr. Sep. Technol. 1998, 12, 641.

(33) Lee, S.A.; Eiteman, M.A. Ground Kenaf Core as a Filtration Aid. Ind. Crops Prod. 2001, 13, 155.

(34) Abe, E.; Hirosue, H.; Yokota, A. Pressure Drop Through a Packed Bed of Binary Mixture. J. Chem. Eng. Jpn. 1979, 12(4), 302.

(35) Li, W.; Kiser, C.; Richard, Q. Effects of filter aids on filter cake compactibility. AIChE Spring National Meeting, April 23-27, 2006b, Orlardo, Florida. 